\title{
B.I.Geltser, T.A.Brodskaya, V.A.Nevzorova \\ Application of functional tests to estimate arterial stiffness in asthmatic patients
}

\begin{abstract}
Summary
The purpose of the research was to study mechanical properties of the aorta using functional tests in patients with asthma. We examined 54 asthmatic patients and 25 healthy volunteers using noninvasive arteriography (arteriograph TensioClinic TL1, TensioMed, Hungary), exercise (PE) and nitroglycerine (NG) tests. Transitory increase in aortal stiffness was observed in patients with exacerbation of severe and moderate asthma. The degree of this increase closely correlated to severity of the disease, ventilation disorders, and hypoxemia. These results suggest higher cardiovascular risk in such patients. Patients with asthma demonstrated amplified or weakened reaction of aortic pulse wave velocity (aPWV) to the PE depending on baseline values of these parameters: higher aPWV corresponded to weaker reaction to PE, and vise versa. As a whole, reduction in arterial stiffness during the NG test in asthma patients was significantly less than in healthy persons. The aPWV reaction to NG was more prominent during exacerbations of severe asthma. Therefore, functional tests investigating mechanical properties of aorta substantially supplemented traditional arteriography. Pathological reaction to PE was seen in some patients with stable asthma and normal aPWV values.
\end{abstract}

\section{Резюме}

Целью исследования было изучение механических свойств аорты у пациентов с бронхиальной астмой (БА) с функциональными пробами. Обследовано 54 больных БА и 25 здоровых добровольцев соответствующего возраста методом неинвазивной артериографии (артериограф TensioClinic TL1 (TensioMed, Венгрия)) с пробами с физической нагрузкой (ФН) и нитроглицерином (НТГ). У больных среднетяжелой и тяжелой БА в период обострения наблюдается транзиторное повышение жесткости аорты. Степень ее увеличения тесно коррелирует с тяжестью заболевания, выраженностью вентиляционных нарушений и уровнем гипоксемии. Эти изменения свидетельствуют об повышении кардиоваскулярного риска у данной категории больных. При проведении пробы с ФН среди пациентов с БА выявляются лица с усиленной и ослабленной реакцией аортальной скорости пульсовой волны (СПВА) на нагрузку. Выраженность реакции СПВА на ФН зависит от исходных значений этих показателей: более высоким базальным значениям СПВА соответствует низкая реакция на ФН и наоборот. В целом в группе больных БА снижение артериальной ригидности после приема НТГ достоверно меньше, чем у здоровых лиц. При обострении тяжелой БА реакция СПВА на НТГ усилена. Степень снижения артериальной ригидности в ответ на НТГ связана с уровнем гипоксемии и длительностью течения заболевания. Использование функциональных тестов для исследования механических свойств аорты существенно расширяет возможности традиционного артериографического исследования. Так, среди больных БА с нормальными значениями СПВА в стадии ремиссии при ФН выявляются лица с патологически измененной реакцией на нагрузку.

В настоящее время избыточная жесткость центральных артерий рассматривается как важный фактор патогенеза сердечно-сосудистых заболеваний [1, 2]. Доказано, что повышение ригидности аорты является независимым предиктором роста кардиоваскулярного риска и смертности среди лиц с артериальной гипертензией и в общей популяции [2, 3]. Наиболее полно изучены особенности формирования и клиническое значение избыточной артериальной ригидности при атеросклерозе, артериальной гипертензии, хронической сердечной недостаточности $[2,4,5]$. В ряде работ представлены данные о нарушении механических свойств центральных артерий у пациентов некардиологического профиля: с хронической почечной патологией, ревматоидным артритом, хронической обструктивной болезнью легких (ХОБЛ) [6, 7]. Приведены результаты, демонстрирующие влияние повышенной ригидности артерий на исход и прогноз этих заболеваний $[6,8]$.

Субстратом стойкого повышения ригидности артерий являются структурно-анатомические изменения в их стенках, характеризующиеся диффузным фиброэластическим утолщением интимы с ремоделированием эндотелия, изменением экстрацеллюлярного матрикса, повышением содержания коллагена, фрагментацией эластической мембраны, инфильтрацией стенок гладкими миоцитами, фиброзом и кальцификацией [1-4]. Известно, что стабильному повышению артериальной ригидности могут предшествовать эпизоды ее транзиторного повышения. Временное увеличение ригидности центральных артерий может носить как физиологический (компенсаторный, при адаптации к физической нагрузке), так и патологический характер [1]. Большое значение в преходящем нарушении механических свойств сосудов придается увеличению напряжения сдвига на эндотелии повышенным давлением, возрастанию концентрации циркулирующих вазоактивных гормонов, медиаторов воспаления, продуктов оксидативного стресса, нарушению функциональной активности сосудистого эндотелия и гладкомышечных клеток $[1,6]$.

В единичных исследованиях продемонстрировано транзиторное повышение ригидности аорты при 
обострении бронхиальной астмы (БА), способствующее росту сердечно-сосудистого риска в этот период заболевания [9]. Однако многие функциональные аспекты изменения механических свойств аорты у данной категории больных до сих пор не изучены.

Известно, что использование функциональных нагрузочных проб существенно повышает информативность проводимых исследований и улучшает качество диагностики. В литературе последних лет имеются лишь единичные работы, характеризующие реакцию скорости распространения пульсовой волны в аорте (СПВА) на предъявляемые воздействия, в частности физическую нагрузку (ФН) [10, 11].

Цель настоящего исследования состояла в изучении механических свойств аорты у больных БА с использованием функциональных проб с ФН и нитроглицерином (НТГ).

\section{Материалы и методы}

Обследованы 54 больных БА, находившихся на лечении в пульмонологическом отделении Городской клинической больницы № 1 г. Владивостока. Средний возраст пациентов составил $45 \pm 3,1$ года, среди них было 24 (44,4 \%) мужчины и 30 (56,6 \%) женщин. Диагноз БА устанавливался в соответствии с рекомендациями GINA. Были выделены группы пациентов со среднетяжелым (31 человек) и тяжелым (23 человека) течением БА. Все они получали стандартную терапию, соответствующую тяжести заболевания. В исследование не включали пациентов с подтвержденной ишемической болезнью сердца, гипертонической болезнью, дислипидемиями, застойной сердечной недостаточностью, почечной и печеночной недостаточностью, сахарным диабетом, онкологическими заболеваниями. Больные БА были обследованы дважды: при поступлении в стационар на фоне обострения и в фазе ремиссии. Контрольную группу составили 25 здоровых некурящих добровольцев соответствующего пола и возраста. Обследование проводилось в одно и то же время суток, после 20-минутного отдыха, в положении сидя. Накануне, минимум за 2 ч, был исключен прием всех препаратов, употребление кофе, курение.

Оценка ригидности центральных артерий проводилась при анализе характеристик пульсовой волны, распространяющейся по аорте, зарегистрированной методом неинвазивной артериографии на артериографе TensioClinic TL1 (TensioMed, Венгрия). Анализировались форма пульсовой кривой, ее амплитуда, длительность периода изгнания левого желудочка (ПИЛЖ), время прохождения отраженной пульсовой волны, показатели величины артериального давления (АД), пульсового давления и частоты сердечных сокращений (ЧСС). Определяли основные характеристики артериальной ригидности: СПВА (м/с) и индекс аугментации (ИА, \%) [12]. На кривой диастолического давления определялись систолический и диастолический индексы площади (ИПС и ИПД, \%) с учетом ПИЛЖ и ЧСС как показатели объемно-временного соотношения перфузии коро- нарных артерий в периоды систолы и диастолы по отношению друг к другу [12].

Артериографическое исследование выполняли в покое, сразу после пробы с ФН проводили тест с 3-минутной ходьбой (дорожка "Тредмил", 4 км/ч (3,0-3,5 MET)), а через 3 мин после пробы с НТГ пациенты принимали 0,5 мг сублингвально. Период между пробами составил 20-30 мин. Изменение СПВА, ИА и ИПС / ИПД после проб оценивали в процентном отношении к исходной величине:

$$
\Delta \mathrm{C} П \mathrm{BA}(\%)=\left(\mathrm{CПВА}_{\phi н}-\mathrm{CПВА}_{\text {покоя }}\right)-100 \% / \mathrm{CПВА}_{\text {покоя }}
$$

Аналогичным образом рассчитывались $\Delta$ ИА $(\%)$ и $\triangle$ ИПС / ИПД (\%).

Сатурацию кислорода крови $\left(\mathrm{SaO}_{2}\right)$ измеряли пальцевым пульсоксиметром 9500 ONYX (Nonin Medical, США).

Результаты обрабатывали с использованием программы Statistica 6,0. Значения представлены в виде средней арифметической \pm стандартное отклонение от средней $(M \pm \sigma)$. Для выявления связи между отдельными показателями применяли метод корреляционного анализа.

\section{Результаты и обсуждение}

В целом по группе больных БА в период обострения ригидность аорты была достоверно большей, чем у здоровых лиц (табл. 1). Это выражалось в увеличении СПВА и ИА как при тяжелом, так и при среднетяжелом течении заболевания $(p<0,001)$. При этом СПВА у пациентов с тяжелой БА почти в 2 раза превосходила значение данного показателя у здоровых лиц. На фоне увеличения ригидности аорты соотношение ИПС / ИПД было смещено в сторону ИПС $(p<0,05)$, что свидетельствовало об ухудшении коронарного кровотока в этот период. Независимо от уровня повышения жесткости артериального русла при обострении, в период ремиссии СПВА, ИА и ИПС / ИПД приближались к контрольным величинам. У большинства пациентов с тяжелой БА (78 \%) значения ИА и ИПС / ИПД были более низкими, чем у здоровых лиц и у больных БА средней тяжести.

Патофизиологическое значение повышения ригидности центральных артерий заключается, прежде всего, в снижении способности сосудистой системы адекватно реагировать на быстро изменяющиеся условия гемоциркуляции, в увеличении постнагрузки на миокард и нарушении коронарного кровотока $[1,3$, $13,14]$. Кроме того, ригидная аорта не справляется с аккумуляцией объема и энергии крови в момент сердечного выброса, в результате чего большая часть его энергии направляется прямо на периферию, где эндотелий артерий подвергается избыточной стимуляции, способствуя дополнительному риску сосу дистых катастроф [5]. Таким образом, в период обострения БА создаются условия для существенного повышения кардиоваскулярного риска, особенно при тяжелом течении заболевания. Транзиторное повышение артериальной ригидности в этот период обусловлено нейрогуморальной активацией 
Таблица 1

Показатели функциональной активности аорть больных БА, по данным непрямой артериографии

\begin{tabular}{|c|c|c|c|}
\hline Показатели & Среднетяжелая БА & Тяжелая БА & Контроль \\
\hline \multirow[t]{2}{*}{ СПВА, м/с } & $7,47 \pm 1,2^{* *}$ & $10,5 \pm 1,3^{\star \star *}$ & $6,2 \pm 1,1$ \\
\hline & $6,3 \pm 1,2^{\#}$ & $6,1 \pm 1,05^{\# \# \#}$ & \\
\hline \multirow[t]{2}{*}{ ИА, \% } & $-25,1 \pm 8,2^{* * *}$ & $14,4 \pm 5,8^{* \star *}$ & $-40,9 \pm 8,1$ \\
\hline & $-38,6 \pm 6,7^{*}$ & $-54,3 \pm 7,8^{* * *, \# \# \#}$ & \\
\hline \multirow[t]{2}{*}{ ипс / ипд } & $1,128 \pm 0,14^{* *}$ & $0,949 \pm 0,09$ & $0,862 \pm 0,15$ \\
\hline & $0,914 \pm 0,06^{\# \#}$ & $0,882 \pm 0,1^{\#}$ & \\
\hline \multirow[t]{3}{*}{$\mathrm{SaO}_{2}, \%$} & $90,8 \pm 1,9^{*}$ & $81,6 \pm 3,7^{* * *}$ & $96,3 \pm 2,6$ \\
\hline & $96,8 \pm 1,4^{\#}$ & $95,2 \pm 2,5^{\# \# \#}$ & \\
\hline & \multicolumn{3}{|c|}{ Проба с физической нагрузкой } \\
\hline \multirow[t]{2}{*}{$\triangle \mathrm{C} \Pi \mathrm{BA}, \%$} & $+37,3 \pm 14,2$ & $+5,8 \pm 7,9^{*}$ & $+21,6 \pm 2,7$ \\
\hline & $+13,1 \pm 3,6^{* * *}$ & $+11,5 \pm 2,8^{\star * *}$ & \\
\hline \multirow[t]{2}{*}{$\Delta$ ИА, $\%$} & $+9,4 \pm 11,2$ & $-8,9 \pm 7,3^{\star \star *}$ & $+10,9 \pm 4,8$ \\
\hline & $-8,2 \pm 2,6^{\star * *}$ & $-3,5 \pm 1,7^{\star \star *}$ & \\
\hline \multirow[t]{3}{*}{ АИПС / ИПд } & $-15,1 \pm 3,2^{* * *}$ & $-4,2 \pm 3,6^{* * *}$ & $+7,2 \pm 2,4$ \\
\hline & $-7,3 \pm 4,3^{* * *}$ & $-2,6 \pm 1,8^{\star \star \star}$ & \\
\hline & \multicolumn{3}{|c|}{ Проба с нитроглицерином } \\
\hline \multirow[t]{2}{*}{$\triangle \mathrm{C} \Pi \mathrm{BA}, \%$} & $-14,8 \pm 6,3^{*}$ & $-53,1 \pm 2,3^{* * *}$ & $-21,9 \pm 6,1$ \\
\hline & $-12,5 \pm 5,2^{*}$ & $-8,4 \pm 4,7^{*}$ & \\
\hline \multirow[t]{2}{*}{$\Delta$ ИА, \% } & $-38,6 \pm 8,0$ & $-89,5 \pm 5,5^{* * *}$ & $-39,5 \pm 7,6$ \\
\hline & $-25,2 \pm 7,1$ & $-28,7 \pm 6,9$ & \\
\hline \multirow[t]{2}{*}{ АИПС / ИПД } & $+24,5 \pm 3,8$ & $+29,9 \pm 6,1$ & $+26,1 \pm 8,7$ \\
\hline & $+2,4 \pm 1,5^{\star \star \star}$ & $+8,3 \pm 3,2^{* * *}$ & \\
\hline
\end{tabular}

Примечание: выше представлены показатели в период обострения БА, ниже - в период ремиссии. Достоверность различий: * - между каждой из групп больных БА и группой контроля, ${ }^{*}$ - между периодом обострения и ремиссии; 1 значок $-p<0,05 ; 2$ - $p<0,01$; $3-p<0,001$

и ассоциированными с ней гиперкинетическими сдвигами кровообращения, а также системным воспалением, гипоксией, оксидативным стрессом, дисфункцией эндотелия $[1,13,15]$. Нормализация показателей жесткости аорты в период ремиссии свидетельствует о преобладающей роли в ее формировании функционального, а не органического компонента.

Проба с ФН, используемая для оценки функционального состояния крупных артерий эластического типа, в частности аорты, дает представление о регулирующей роли этого сосуда при интенсификации кровообрашения. Индуцированное ФН повышение ударного и минутного объемов крови, ЧСС, АД в норме сопровождается увеличением СПВА, соразмерным интенсивности ФН $[10,11]$. Увеличение СПВА в данном случае характеризует степень целенаправленного компенсаторного повышения жесткости крупных артерий, необходимого для перемещения увеличенного объема крови в сосудистой системе, и связано, прежде всего, с положительным тонотропным действием симпатической нервной системы [10]. Можно предположить, что, чем выше потенциальная способность аорты к сопротивлению избыточному центральному АД и чем лучше ее демпфирующие свойства, тем более значительный уровень $\triangle$ СПВА будет наблюдаться при ФН. Известно также, что увеличение СПВА лимитировано биологическими возможностями сердечно-сосудистой системы [10]. В нашем исследовании у здоровых лиц проба с ФН в определенной мере увеличивала СПВА и ИА, но не приводила к существенному изменению условий коронарной перфузии.

При анализе результатов пробы с ФН у пациентов с БА наблюдался достаточно широкий разброс показателей ригидности аорты (табл. 1, рисунок). В период обострения заболевания у большинства больных среднетяжелой БА (62 \%) происходило чрезмерное нарастание СПВА в ответ на выполнение ФН в среднем на 74,3\% $(p<0,001)$. В некоторых случаях показатель $\triangle$ СПВА достигал $+166 \%$ (в абсолютных значениях СПВА составляла 14,8 м/с). У меньшей части пациентов реактивность аорты была сниженной (+12,2 \%). Прослеживалась следующая закономерность: избыточная реакция СПВА на ФН наблюдалась у лиц с незначительно увеличенными значениями СПВА в покое, а сниженная - у лиц с исходно более высокими показателями. Показатель ИА у $58 \%$ пациентов со среднетяжелой БА при ФН повышался на 36,8 \%. Для лиц с исходно более высокими значениями этого показателя было характерно незначительное снижение ИА (в среднем на 4,3\%). Реакция СПВА на ФН у пациентов с обострением тяжелой БА была однонаправленной. В целом по данной группе реакция аорты на ФН оказалась достоверно сниженной $(p<0,05)$. Так, у $60 \%$ больных значение $\triangle$ СПВА находилось в отрицательном диапазоне и составило в среднем $-6,1 \%$, а у $40 \%$ - в положительном $(+15,4 \%)$. Реакция ИА на ФН в этой группе пациентов достоверно отличалась от контроля, мало изменяясь по сравнению с исходными величинами.

Как при среднетяжелом, так и при тяжелом течении БА динамика изменения СПВА и ИА на фоне ФН была достаточно тесно связана с исходными значениями этих показателей в покое $(r=-0,35$ и $r=-0,41)$. Направление связи указывало на то, что более высоким базальным показателям СПВА соответствовала более низкая реакция на ФН $(p<0,001)$.

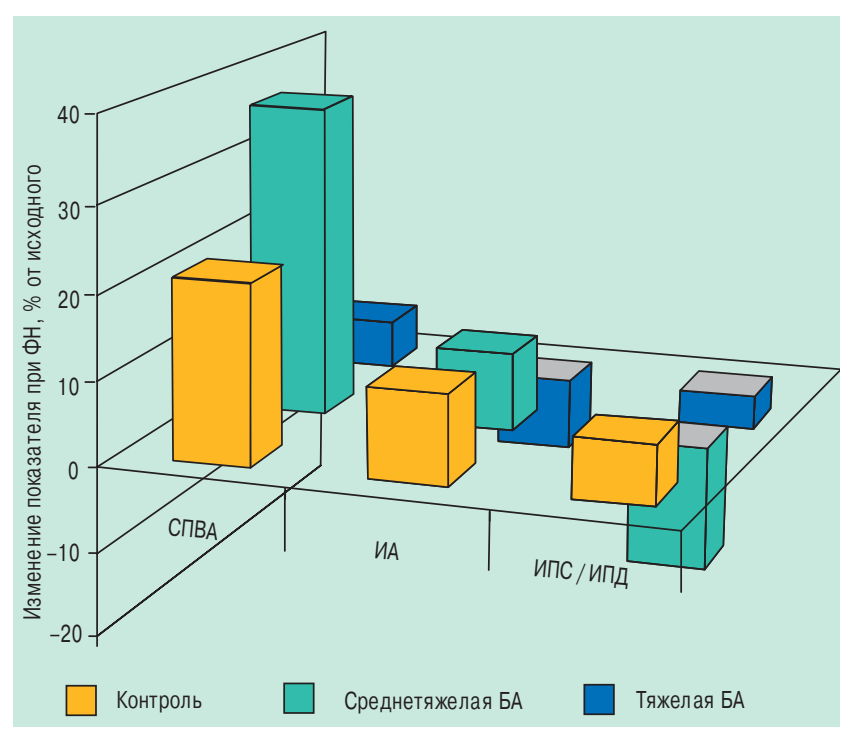

Рисунок. Динамика показателей неинвазивной артериографии при проведении пробы с ФН у здоровых лиц и больных БА в период обострения 
Динамика индекса ИПС / ИПД при проведении теста с ФН была направлена противоположно контрольной группе. У $87 \%$ пациентов с БА при ФН индекс ИПС / ИПД снижался, а не повышался, как У здоровых лиц $(p<0,01)$. У больных БА при ФН соотношение индексов кровенаполнения коронарных артерий смещалось в сторону преобладания ИПД, что соответствовало улучшению условий коронарной перфузии.

В период ремиссии у больных БА показатели жесткости аорты в покое не превышали контрольный уровень. Однако реакция СПВА на ФН была достоверно сниженной как при тяжелом, так и при среднетяжелом течении заболевания (табл. 1). В отличие от периода обострения, разброс значений СПВА при ФН был незначительным. Динамика изменений ИА и соотношения ИПС / ИПД была противоположной по отношению к группе здоровых $(p<0,001)$.

Влияние пробы с НТГ на $\triangle$ СПВА связано с эндотелий-независимым расслаблением миоцитов мелких артерий мышечного типа, приводящим к снижению периферического и общего сосудистого сопротивления [16]. В нашем исследовании тест с НТГ у здоровых лиц вызывал уменьшение СПВА и ИА, а соотношение ИПС / ИПД незначительно изменялось в сторону увеличения за счет возрастания ЧСС. Реакция СПВА и ИА на нитраты у больных БА по направленности соответствовала здоровым лицам. Однако при среднетяжелом течении заболевания она была менее выражена в периоды обострения и ремиссии, при тяжелом - в период обострения достоверно повышалась, а в период ремиссии - снижалась (табл. 1). Индекс ИПС / ИПД при пробе с НТГ в период обострения у всех больных изменялся соответственно контрольной группе, а в период ремиссии его реакция была также сниженной. Общая тенденция к снижению чувствительности к нитратам у больных БА, скорее всего, носит гипоксемический характер $[17,18]$. В то же время усиленная реакция СПВА и ИА к НТГ в период обострения тяжелой БА может быть обусловлена повышением чувствительности гладких миоцитов к экзогенному оксиду азота [17]. Подтверждает адаптационную гипотезу этих изменений факт возрастания реактивности СПВА и ИА на НТГ по мере утяжеления БА, на что указывает отрицательная корреляция показателей $\triangle$ СПВА и $\Delta$ ИА с длительностью и тяжестью заболевания (табл. 2).

При проведении корреляционного анализа установлена положительная взаимосвязь выраженности изменений СПВА и ИА при ФН с показателем $\mathrm{SaO}_{2}$ и отрицательная - с длительностью БА (табл. 2). Индекс $\triangle$ ИПС / ИПД при пробе ФН тесно коррелировал с длительностью БА, однако направление связи было противоположным по сравнению с $\triangle$ СПВА. $\mathrm{C}$ показателями ОФВ $1 \mathrm{BaO}_{2}$ были тесно связаны значения $\triangle$ СПВА, $\triangle$ ИА и $\triangle$ ИПС / ИПД при пробе с НТГ.

Интересны полученные данные усиленной реакции сосудов больных БА в ответ на ФН и НТГ при
Таблица 2

Корреляция между некоторыми клиническими характеристиками, гипоксией и показателями артериальной ригидности у больных БА

\begin{tabular}{|c|c|c|c|}
\hline \multirow{2}{*}{$\begin{array}{c}\text { Показатели непрямой } \\
\text { артериографии }\end{array}$} & \multicolumn{3}{|c|}{ Характеристики больных БА } \\
\hline & Длительность БА & $0 \Phi \mathrm{B}_{1}$ & $\mathrm{SaO}_{2}$ \\
\hline$\triangle$ ССПА при ФН & $-0,69^{* *}$ & 0,22 & $0,40^{*}$ \\
\hline 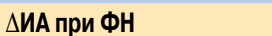 & $-0,41^{*}$ & 0,12 & $0,28^{*}$ \\
\hline АИПС / ИПД при ФН & $0,81^{* * *}$ & $-0,21$ & $-0,23$ \\
\hline$\triangle$ СПВА, проба с НТГ & $-0,45^{*}$ & $0,87^{* * *}$ & $0,95^{\star * *}$ \\
\hline АИА, проба с НТГ & $-0,51^{* *}$ & $0,92^{* * *}$ & $0,96^{* * *}$ \\
\hline АИПС / ИПД, проба с НТГ & 0,23 & $-0,89^{* * *}$ & $-0,84^{* * *}$ \\
\hline
\end{tabular}

Примечание: ОФВ ${ }_{1}$ - объем форсированного выдоха за 1-10 ; $^{*}-p<0,05,{ }^{* *}-p<0,01$, ${ }^{* * *}-p<0,001$.

обострении БА. При этом в период ремиссии реакция на ФН и НТГ несколько ослабевала. Предварительный анализ показал вероятную взаимосвязь такого состояния с выраженностью вентиляционных нарушений и гипоксемией, а также с длительностью течения БА. Очевидно, наблюдаемые изменения представляют собой результат эффективной работы адаптационных механизмов в ответ на неоднократные эпизоды "раздражения" эндотелиоцитов и гладких миоцитов факторами агрессии БА в периоды обострения. Однако требуется дальнейшее исследование данного вопроса для выяснения природы наблюдаемых явлений.

\section{Заключение}

1. У больных среднетяжелой и тяжелой БА в период обострения наблюдается транзиторное повышение ригидности аорты. Степень ее увеличения тесно коррелирует с тяжестью заболевания, выраженностью вентиляционных нарушений и уровнем гипоксемии. Эти изменения свидетельствуют об увеличении кардиоваскулярного риска у данной категории больных.

2. При проведении пробы с ФН среди пациентов с БА выявляются лица с усиленной и ослабленной реакцией СПВА на предъявляемое воздействие. Выраженность реакции СПВА и ИА на ФН зависит от исходных значений этих показателей: более высоким базальным значениям СПВА соответствует низкая реакция на ФН и наоборот.

3. В целом в группе больных БА снижение артериальной ригидности после приема НТГ достоверно меньше, чем у здоровых лиц. При обострении тяжелой БА реакция СПВА и ИА на НТГ усилена (в среднем на $30 \%$ ). Степень снижения артериальной ригидности в ответ на НТГ связана с уровнем гипоксемии и длительностью течения БА.

4. Использование функциональных тестов для исследования механических свойств аорты существенно дополняет возможности традиционного артериографического исследования. Так, среди больных БА с нормальными значениями СПВА в стадии ремиссии при ФН выявляются лица с патологически измененной реакцией на нагрузку. 


\section{Литература}

1. Zieman S.J., Melenovsky V., Kass D.A. Mechanisms, pathophysiology, and therapy of arterial stiffness. Arterioscler. Thromb. Vasc. Biol. 2005; 25 (5): 932-943.

2. Недогода С.В., Чаляби Т.А. Сосудистая жесткость и скорость распространения пульсовой волны: новые факторы риска сердечно-сосудистых осложнений и мишени для фармакотерапии. Consilium Medicum. Болезни сердца и сосудов. 2006; 1 (4). http://www.consiliummedicum.com/media/bss/06_04/34.shtml.

3. Laurent S., Cockcroft J., Van Bortel L. et al. the European Network for Non-invasive Expert consensus document on arterial stiffness: methodological issues and clinical applications. Eur. Heart J. 2006; 27 (21): 2588-2605.

4. Орлова Я.А., Агеев Ф.Т. Жесткость артерий как интегральный показатель сердечно-сосудистого риска: физиология, методы оценки и медикаментозной коррекции. Сердце 2006; 5 (2): 65-69.

5. Laurent S., Katsahian S., Fassot C. and al. Aortic stiffness is an independent predictor of fatal stroke in essential hypertension. Stroke 2003; 34 (5): 1203-1206.

6. Roman M.J., Devereux R.B., Schwartz J.E. et al. Arterial Stiffness in Chronic Inflammatory Diseases Fifth International Workshop on Structure and Function of Large Arteries Hypertension. 2005; 46: 194.

7. Бродская Т.А., Гельцер Б.И. Особенности механических свойств центральных артерий у больных ХОБЛ. В кн.: Белялов Ф.И.(ред.). Сочетанные заболевания внутренних органов в терапевтической практике. Сборник материалов I межрегиональной конф. Иркутск; 2007. 56-59.

8. Safar M.E., London G.M, Plante G.E. Arterial stiffness and kidney function. Hypertension 2004; 43: 163-168.

9. Бродская Т.А., Гельцер Б.И., Невзорова В.А., Моткина Е.В. Клинико-функциональная оценка артериальной ригидности при бронхиальной астме. Клиническая медицина. 2007; 6: 17-23.
10. Карпман В.Л. Сердечно-сосудистая система и транспорт кислорода при мышечной работе. В кн.: Сборник, посвященный 25-летию кафедры спортивной медицины им. проф. В.Л.Карпмана РГАФК. М.; 1994. 12-39.

11. DeVan A.E., Anton M.M., Cook J.N. et al. Acute effects of resistance exercise on arterial compliance. J. Appl. Physiol. 2005; 98: 2287-2291.

12. Arteriograph TensioClinic and its program TensioClinic. User's manual. Early diagnosis of arteriosclerosis. http://www.tensiomed.com/eng/tclin.

13. Cohn J.N., Quyyumi A.A., Hollenberg N.K., Jamerson K.A. Markers of malign across the cardiovascular continuum: interpretation and application. Surrogate Markers for Cardiovascular Disease. Functional Markers. Circulation 2004; 109: IV31-IV46.

14. Kass D.A. Ventricular arterial stiffening. Integrating the Pathophysiology. Fifth International Workshop on Structure and Function of Large Arteries. Hypertension 2005; 46: 185-191.

15. Бродская Т.А., Невзорова В.А., Гельцер Б.И., Моткина Е.В. Дисфункция эндотелия и болезни органов дыхания. Тер. арx. 2007; 3: 76-84.

16. Pauca A.L., Kon N.D., O'Rourke M.F. Benefit of glyceryl trinitrate on arterial stiffness is directly due to effects on peripheral arteries. Heart 2005; 91: 1428-1432.

17. Блажкко В.И., Ефимов В.В., Бондарь Т.Н., Талалай И.В. Роль окиси азота в реакции адаптации к гипоксии у больных хроническими обструктивными заболеваниями легких. Укр. тер. журн. 2005; 2: 52-55.

18. Манак Н.А., Козич И.А., Карпова И.С. Патогенетические механизмы толерантности к нитратам и возможные пути коррекции. Кардиология СНГ 2003; 5: 26-29.

Поступила 01.08.07 (c) Коллектив авторов, 2008 удк 616.248-07:616.13-072.7 